\title{
A Dyshidrosis-Like Variant of Adult T-Cell Leukemia/ Lymphoma With Clinicopathological Aspects of Mycosis Fungoides. A Case Report
}

\author{
Achiléa L. Bittencourt, PhD, * Karla Mota, MD, † Rodrigo F. Oliveira, MS, * and Lourdes Farré, PhD $\neq$
}

\begin{abstract}
Adult T-cell leukemia/lymphoma (ATL) is an aggressive type of leukemia/lymphoma associated with the human T-cell lymphotropic virus (HTLV-I). We describe an adult male patient clinically and pathologically diagnosed as mycosis fungoides and treated with chemotherapy after which complete involution of the lesions occurred. The disease relapsed with confluent dyshidrosis-like vesicles on the palmoplantar regions, followed by disseminated vesiculopapules and associated lymphocytosis. A serological test performed at this time revealed HTLV-I infection, and a diagnosis of chronic ATL was made. Monoclonal integration of HTLV-I was detected in peripheral blood mononuclear cells by inverse long polymerase chain reaction. A skin biopsy revealed spongiosis, Pautrier abscesses, and intraepidermal vesicles with atypical lymphocytes and an infiltration of small and atypical CD4 $4^{+}$lymphocytes in the superficial dermis. Proliferative index (Ki-67) was 70\%. This is the first reported vesicular cutaneous ATL with confirmation of HTLV-I proviral integration. The delay that occurred in diagnosing ATL was due to the fact that mycosis fungoides and ATL may present the same clinical, histopathological, and immunohistochemical features.
\end{abstract}

Key Words: adult T-cell leukemia/lymphoma, mycosis fungoides, HTLV-I infection

(Am J Dermatopathol 2009;31:834-837)

\section{INTRODUCTION}

Adult T-cell leukemia/lymphoma (ATL) is an aggressive mature T-cell malignancy associated with the human T-cell lymphotropic virus type I (HTLV-I) that is characterized by a short survival time and a poor response to chemotherapy. ${ }^{1}$ It is clinically classified as the following types: acute, chronic, lymphomatous, smoldering, or primary cutaneous tumoral. ${ }^{1,2}$

From the *Departments of Pathology; †Internal Medicine, Hospital Universitário Prof. Edgard Santos, Federal University of Bahia, Salvador, Bahia, Brazil; and \$Laboratory of Experimental Pathology (LAPEX), CPqGM-FIOCRUZ, Salvador, Bahia, Brazil.

Supported by Conselho Nacional de Pesquisa (CNPq) and Fundação de Apoio a Pesquisa do Estado da Bahia (FAPESB).

The authors have no conflicts of interest.

Reprints: Achiléa L. Bittencourt, PhD, Serviço de Anatomia Patológica, Hospital Universitário Prof. Edgard Santos, Rua Dr. Augusto Viana, $\mathrm{s} / \mathrm{n}^{\circ}$, Canela-CEP 40.110-060, Salvador, Bahia, Brazil (e-mail: achilea@uol. com.br).

Copyright $(\subset 2009$ by Lippincott Williams \& Wilkins
The disease affects the skin in $43 \%-72 \%$ of cases $^{2}$ and manifests in the skin as erythroderma, plaques, papules, and less frequently as nodules and tumors. ${ }^{3}$ In 2002, Michael et $\mathrm{al}^{4}$ described the clinical and histopathological features of a case of bullous acute ATL. Previously, another case of vesicular cutaneous ATL had been described, albeit without histopathological confirmation of the blisters. ${ }^{5}$

Vesiculobullous lesions have been reported in around 30 cases of mycosis fungoides (MF)/Sézary syndrome, types of cutaneous T-cell lymphomas unassociated with the HTLV-I. ${ }^{6-13}$ The blisters were generalized appearing either on normal skin or within typical MF lesions. ${ }^{7}$ In 2 cases, the lesions predominantly involved the palmoplantar region simulating dyshidrosis. ${ }^{8,9}$

The aim of this article is to describe the first case of vesicular ATL with confirmation of HTLV-I proviral integration.

\section{CASE REPORT}

A 38-year-old male patient, born and living in São Paulo, Brazil, presented a $3 \frac{1}{2}$ years history of disseminated cutaneous papular lesions. He also had diabetes. Four months after the onset of symptomatology, he was submitted to biopsies of the skin and lung and received histopathological diagnosis of MF (August 2004). A tomography revealed nodules at the pulmonary bases, the biopsy of which confirmed the presence of lymphoma. At this time, lymphocytosis varying from 4200 to 9000 lymphocytes per cubic millimeter and a mild increase in lactate dehydrogenase were observed. The patient received a chemotherapy regimen with CHOP (cyclophosphamide, doxorubicin, vincristine, and prednisone) after which the lesions disappeared. He moved to Salvador, Bahia, and in his last follow-up (September 2007), no clinical changes were observed and tests revealed no abnormality. However, 1 month later, confluent vesicles appeared on both palmoplantar regions and dorsum of the feet with desquamation and erythema, simulating dyshidrosis (Figs. 1A, B). This was followed by the development of small papulovesicular lesions on the trunk, scalp, and genitalia. At this time, chest and cervical tomographies were normal but abdominal tomography revealed a small nodule in the paraortic region. The patient also presented a lymphocyte count of 8700 lymphocytes per cubic millimeter, $13 \%$ atypical lymphocytes, but no increase in serum levels of lactate dehydrogenase or calcium. A serologic study revealed the patient to be HTLV-I positive and human immunodeficiency virus negative. TCR $\gamma$ gene rearrangement analysis performed in peripheral blood mononuclear cells showed monoclonality. Moreover, monoclonal integration of HTLV-I was detected in peripheral blood mononuclear cells by inverse long polymerase 

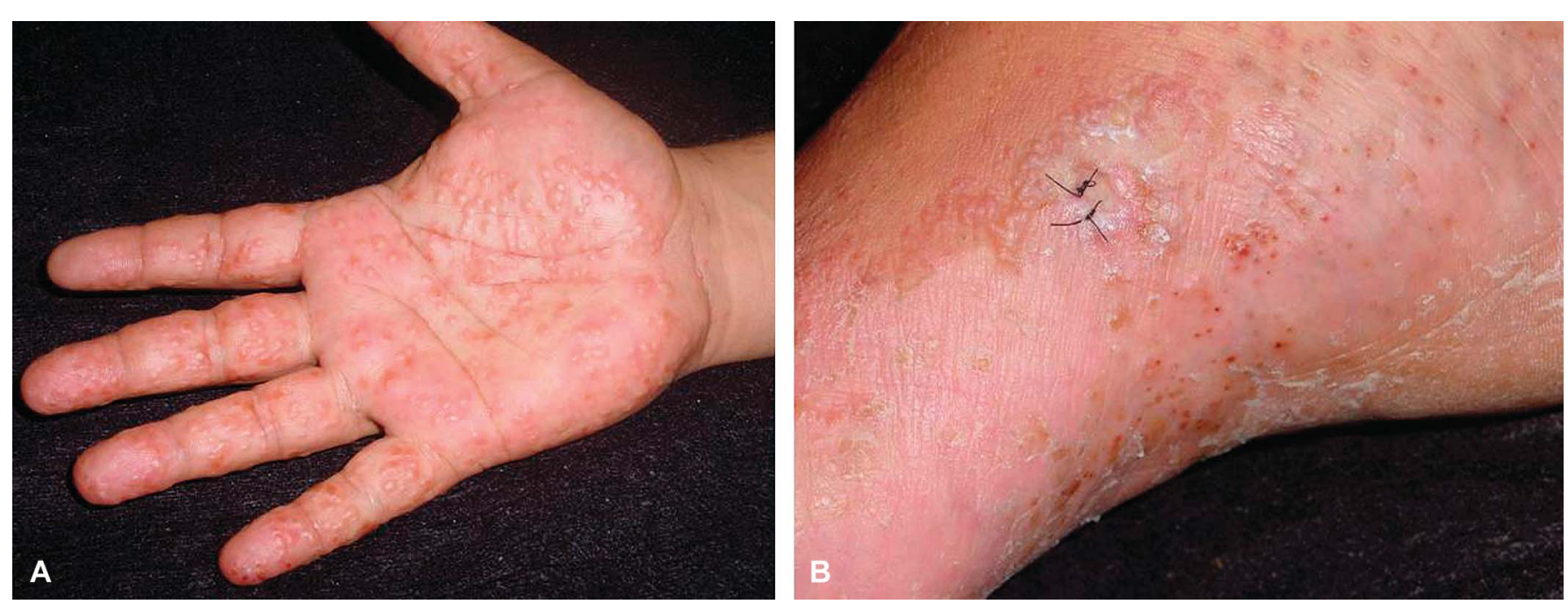

FIGURE 1. A dyshidrosis-like pattern. A, Many vesicles in the palm of the right hand. B, Extensive, scaly, and erythematous plaque on the sole and internal border of the right foot with confluent vesicles.

chain reaction (Fig. 2). ${ }^{14} \mathrm{~A}$ bone marrow biopsy revealed the presence of lymphoma. The pulmonary biopsy performed in August 2004 was revised, and a new skin biopsy was carried out on 1 vesicular lesion. The patient was treated with 1 cycle of CHOP followed by interferon $\alpha$ plus zidovudine without improvement. The patient died a month later as a result of uncontrolled diabetes and pneumonia.

\section{Histopathology and Immunohistochemistry}

The skin biopsy showed in the epidermis spongiosis, a marked epidermotropism of lymphocytes, Pautrier abscesses, and various and large intraepidermal vesicles with atypical lymphocytes (Fig. 3A). In the superficial dermis, an infiltration of small and atypical

M

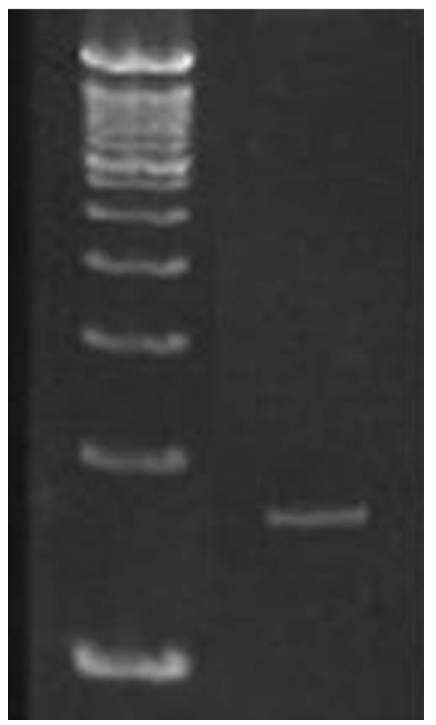

FIGURE 2. Analysis of proviral HTLV-I integration by inverse long PCR. The PCR product was visualized in a polyacrylamide gel. Lane M, DNA molecular weight marker 100 base pairs (Invitrogen); lane $\mathrm{P}$, the patient. PCR, polymerase chain reaction. lymphocytes was seen (Fig. 3B). The lymphocytes were $\mathrm{CD} 2^{+}, \mathrm{CD}^{+}$, $\mathrm{CD} 4^{+}, \mathrm{CD}^{+}, \mathrm{CD}^{-}, \mathrm{CD} 8^{-}, \mathrm{CD} 20^{-}, \mathrm{CD} 25^{+}$, and $\mathrm{CD} 79 \mathrm{a}^{-}$. The $\mathrm{Ki}-67+$ lymphocytes were seen in the epidermis, dermis, and within the vesicle (Fig. 4). The proliferative index varied in different areas of the biopsy from $40 \%$ to $80 \%$ (mean $62 \%$ ). The pulmonary biopsy revealed nodules with atypical lymphocytes with the same phenotype of the skin lesion; however, the proliferative index was much lower $(3 \%)$.

\section{DISCUSSION}

Histologically, ATL may present patterns similar to those of MF, peripheral T-cell lymphoma, and anaplastic large cell lymphoma. ${ }^{2}$ This patient presented the chronic type of ATL with skin and pulmonary involvement, histologically similar to MF, which was his initial diagnosis.

The median survival time of patients with chronic ATL varies from 18 to 24 months ${ }^{1,2}$; however, this patient survived for much longer (38 months) and did not die as a result of ATL. It is known that certain variables, such as the smoldering and chronic clinical forms, MF-like histological pattern, and small- and medium-sized cell morphology, are related to a better prognosis; however, this patient presented a high proliferative index in the cutaneous lesion, an aspect that is considered as an unfavorable variable. ${ }^{2}$

As in the majority of the cases of vesiculobullous cutaneous lymphoma, ${ }^{7}$ the vesicular lesions were of late onset in the present case. One interesting aspect was the morphology and localization of the vesicles on the palmoplantar regions, simulating a dyshidrotic eruption as has been previously reported in vesiculobullous $\mathrm{MF}^{8}$

The mechanism of blister formation in these lymphomas is unclear. Histologically, the blisters are reported as subcorneal, intraepidermal, and subepidermal. ${ }^{7}$ Intraepidermal blisters, such as those seen in the present case, may appear secondary to the confluence of Pautrier microabscesses.

It is important to emphasize that, in addition to other dermatological aspects, ATL may rarely present as a vesicular 

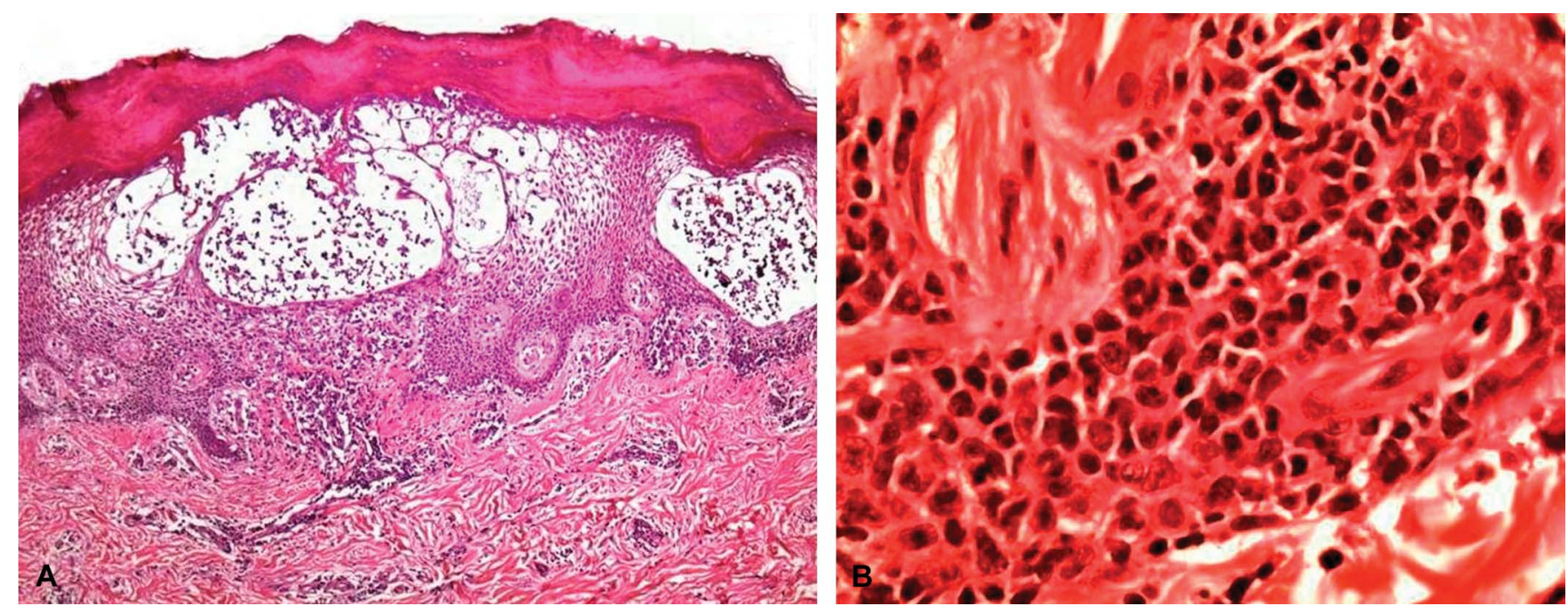

FIGURE 3. Skin biopsy. A, The epidermis shows spongiosis, a marked epidermotropism of lymphocytes, and large intraepidermal vesicles with atypical lymphocytes $(\mathrm{H} \& \mathrm{E}$, original magnification $\times 50)$. B, Infiltration of atypical lymphocytes in the dermis $(\mathrm{H} \& \mathrm{E}$, original magnification $\times 500)$. $\mathrm{H} \& \mathrm{E}$, hematoxylin and eosin.

disease. The present case was the only one found among 52 cases of ATL with cutaneous presentation diagnosed in Bahia, Brazil. $^{3}$ As mentioned above, MF and ATL may present the same clinical, histopathological, and immunohistochemical features, and this may explain the delay in the diagnosis of ATL in the present case.

The diagnosis of ATL requires confirmation of the presence of serum antibodies against HTLV-I and, whenever possible, the presence of integrated proviral sequences to make the differential diagnosis between ATL and other types of lymphoma such as MF, peripheral T-cell lymphoma, and anaplastic large cell lymphoma, occurring in HTLV-I

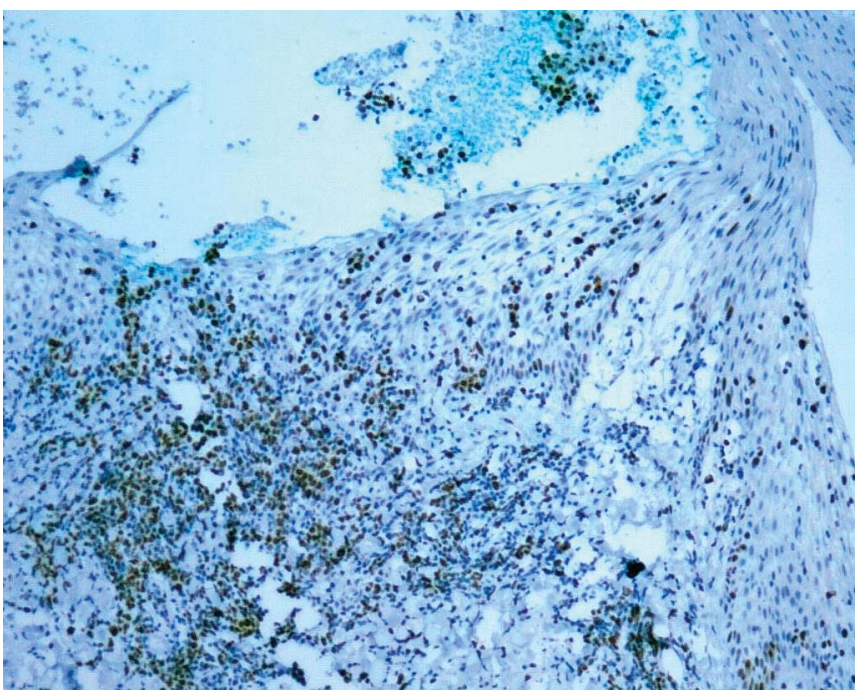

FIGURE 4. The lower half of an intraepidermal vesicle. See many KI-67+ lymphocytes in the dermis, epidermis, and within the vesicle (standard streptavidin-biotin-peroxidase technique, original magnification $\times 64)$. carriers. $^{2,15}$ This differentiation is important because the prognosis and treatment of ATL are different from those of other types of lymphoma. ${ }^{15}$

Confirmation of HTLV-I proviral integration in the present case unequivocally demonstrates the relationship between the virus and the lymphoma. To the best of our knowledge, this is the first case of ATL with cutaneous vesicular lesions in which monoclonal integration of HTLV-I was demonstrated. Considering that ATL may mimic MF, HTLV-I infection should be investigated in all these T-cell lymphomas in endemic areas.

\section{ACKNOWLEDGMENT}

We thank Dr. Vera Luiza Capelozzi for providing the paraffin blocks of the lung biopsy.

\section{REFERENCES}

1. Shimoyama M; members of the Lymphoma Study Group. Diagnostic criteria and classification of clinical subtypes of adult T-cell leukaemialymphoma. Br J Haematol. 1991;79:428-437.

2. Bittencourt AL, Vieira MG, Brites CR, et al. Adult T-cell leukemia/ lymphoma (ATL) in Bahia, Brazil: analysis of prognostic factors in a group of 70 patients. Am J Clin Pathol. 2007;128:875-882.

3. Bittencourt AL, Barbosa HS, Vieira MD, et al. Adult T-cell leukemia/ lymphoma (ATL) presenting in the skin: clinical, histological and immunohistochemical features of 52 cases. Acta Oncol. 2009;48:598-604.

4. Michael EJ, Shaffer JJ, Collins HE, et al. Bullous adult T-cell lymphoma/ leukemia and human T-cell lymphotropic virus-1 associated myelopathy in a 60-year-old man. $J$ Am Acad Dermatol. 2002;46:S137-S141.

5. Chan HL, Su IJ, Kuo TT, et al. Cutaneous manifestations of adult T cell leukemia/lymphoma. Report of three different forms. J Am Acad Dermatol. 1985;13:213-219.

6. Pearce A, Reid C, Gramp A, et al. A 30-year history of CD4+ vesiculobullous mycosis fungoides and multiple visceral malignancies. Australas $J$ Dermatol. 2007;48:46-49.

7. Bowman PH, Hogan DJ, Sanusi ID. Mycosis fungoides bullosa: report of a case and review of the literature. J Am Acad Dermatol. 2001;45: 934-939. 
8. Jakob T, Tiemann M, Kuwert C, et al. Dyshidrotic cutaneous T-cell lymphoma. J Am Acad Dermatol. 1996;34:295-297.

9. Héliot I, Beylot-Barry M, Vergier B, et al. Cutaneous T-cell lymphoma bullosa: 2 cases Ann Dermatol Venereol. 2003;130:639-642.

10. Ono A, Isomura I, Isogai Z, et al. A case of bullous Sézary syndrome. $J$ Dermatol. 2004;31:1027-1031.

11. Zina G, Bernengo MG, Zina AM. Bullous Sézary syndrome. Dermatologica. 1981;163:25-33.

12. Betlloch I, Quiles RD, Jorda-Cuevas F, et al. Bullous Sézary syndrome. Ann Dermatol Venereol. 1985;112:825-829.
13. Aractingi S, Robert C, Reygagne P, et al. Sezary syndrome with palmoplantar bullous lesions. Ann Dermatol Venereol. 1992;119: 894-897.

14. Etoh K, Tamiya S, Yamaguchi K, et al. Persistent clonal proliferation of human T-lymphotropic virus type I-infected cells in vivo. Cancer Res. 1997:57:4862-4867.

15. Tsukasaki K, Hermine O, Bazarbachi A, et al. Definition, prognostic factors, treatment, and response criteria of adult T-cell leukemialymphoma: a proposal from an International Consensus Meeting. J Clin Oncol. 2009;27:453-459. 